\title{
The Characteristics of the Chinese People Surnamed Huang
}

\author{
Chunping Zhang \\ Shangqiu Medical College \\ Shangqiu, China 476000
}

\begin{abstract}
The Chinese nation has common characters and each nation has its own characteristics. What's more, each ethnic group also has its own characteristics. The main characteristics of the people surnamed Huang are: the reality of a large population and wide distribution, the traditional virtues of etiquette and filial piety, pioneering spirit of entrepreneurship from all over the word, the unique way of reciting poems for identifying clans.
\end{abstract}

Keywords-People Surnamed Huang; clansmen;
characteristics

\section{INTRODUCTION}

The Chinese nation has common characters and each nation has its own characteristics. What's more, each ethnic group also has its own characteristics. This article will give a brief overview of the characteristics and the most prominent manifestation of the people surnamed Huang.

\section{The REALITY OF A LARGE POPULATION AND WIDE DISTRIBUTION}

The history has different records about the number of surnames that have appeared in Chinese history and are used at present in all ages, so the statements are different. The Surname and Compiling written by Lin Bao in Tang dynasty includes 1231 surnames, The Explain of Surname written by Shao $\mathrm{Si}$ in Song dynasty includes 2568 surnames, The Literature Review written by Ma Duanlin in Yuan dynasty includes 3736 surnames, The Continued Literature review written by Wang Qi in Ming dynasty includes 4657 surnames, The Dictionary of Chinese Ancient and Modern Surnames written by modern scholars Dou Xuetian includes 12000 surnames. We think the more authoritative one is The Dictionary of Chinese Surnames written by Du Ruopu and Yuan Yida who in Chinese Academy of Sciences Institute of genetics according to the national census data for the fourth time and Distribution of Surnames in Taiwan. The book statistics: There are 11969 Chinese surnames, including 5372 single surnames, 5327 double surnames and 2313 surnames of three Chinese characters or above.

The data from the fifth national census in 2001 showed: the total population is over 1.2 billion in china (no Hong Kong, Macao and Taiwan), including more than 1.1 billion Han people and about more than 0.100 billion minorities. Huang is in the 8th place after Li, Wang, Zhang, Liu, Chen, Yang and
Zhao according to the number of the surnames. The number of Huang family is about 29 million people, accounting for about $2.3 \%$ of the total population.

The sixth national census in 2010 announced: The total population of mainland China is more than 1.3 billion people, the population of Hongkong is about 7,100,000 people, the population of Macao is about 55 people, and the population of Taiwan is about 2300,000 .

The population of Huang is about $31,000,000$ in the sixth census and the eighth place in the fifth census was ranked seventh place about the population (before the surname Zhao). The total population of Huang is about $42,000,000$ people, accounting for more than $3 \%$ of the total population if Hongkong, Macao, Taiwan and ethnic minorities are included.

The population distribution of Huang is extremely extensive, mainly in the south of the Yangtze River. Huang population in Guangdong, Sichuan, Hunan, Guangxi, Jiangxi five provinces accounted for more than half of the population of all the Huang population in the Han nationality and in China. The area with the highest density of Huang population per unit area is Chaozhou, Guangdong, Shantou and Pearl River Delta, Quanzhou of Fujian, eastern of Hunan, Ganzhou of Jiangxi and southeast of Sichuan. There are more than 10 people in per square kilometer of Huang. Among them, the population of Huang is over 30 people in per square kilometer and the densely packed central area has more than 50 in people per square kilometer in Jieyang and Zhanjiang of Guangdong.

As for the province, Huang has the largest population in Guangdong, with more than 7 million people, accounting for 8 percent of the total population, accounting for $23 \%$ of the population of Huang. Huang population ranks first in Guangxi, with 3.7 million people, ranks seventh in Sichuan, with3.8 million people, also ranks seventh in Hunan, with 2.2 million people, ranks third in Fujian, with more than 2 million people, ranks fifth in Jiangxi, with 1.9 million people, ranks eighth in Hubei, with 1.7 million people, also ranks eighth in Jiangsu, with 1.6 million people, ranks sixth in Zhejiang, with 1.45 million people, ranks ninth in Anhui, with 1.4 million people, ranks ninth in Yunnan, with 1 million people. The 12 provinces have a population of 35 million of Huang people and the total coverage covers $70 \%$ of the land area. There are 1.5 million in Taiwan and it is second only to Chen and Lin, ranks third. So there is a saying that "Chen and Lin take a half Fujian region, and Huang and Zheng are everywhere in Fujian" 
In the whole world, the total population of Huang is about $75,000,000$. Huang is one of the most common surnames for overseas Chinese. Huang is the first most common surname for Chinese in the United States, the second common surname for Chinese in the Philippines, the second common surname for Chinese in Singapore, the third common surname for Chinese in Malaysia, the seventh common surname for Chinese in Vietnam. There are 400 thousand Chinese surnamed Huang in Thailand and 600 thousand Chinese surnamed Huang in Korea.

\section{The TRAditionAl VIRTUES OF RESPECT FOR PARENTS AND FILIAL PIETY}

China has been known as a Formal state" since ancient times. The Analects of Confucius regarded rites as the norm of morality, "Guide the people with morality and assimilate them with ritual system". Han Feizi saw "gift" as the criterion of moral behavior, "Courtesy, why love is the appearance, the reason is that many articles have been concentrated, the relationship between the king and the minister is like the relationship between father and son, and the high and low level of identity is used to distinguish one's ability or talent."

As the saying goes, "First of all, take filial piety." Filial Piety said: "the filial piety, is the basis of virtue education." The Analects of Confucius said: "The filial piety also means the benevolence of the people!" It can be seen that filial piety is the basis of virtue. It is also the foundation and core of traditional Chinese culture. Filial piety is the most important of all virtues. "Taking good care of parents is filial," said Zhu Xi, a scholar of the song dynasty. Respect parents and filial piety, is the traditional virtue of the Chinese nation, all previous dynasties official writings are strongly advocated filial piety. In recognition of filial piety, there is often a special section project called "loyalty and filial piety", which records the deeds of honoring filial piety and filial piety. In respect of filial piety, the historical Huang clan is very famous and can be said to be the epitome of traditional filial piety in China. For example, in the popular 24 filial piety, Huang family has two characters: one is Huang Xiang in the Han dynasty; another is Huang Tingjian in the Song dynasty. Huang Xiang can be the chief representative of Chinese filial piety. Spread for thousands of years, the book Three Character Classic said "nine years old, warm at the table, Huang Xiang is filial piety and filial piety". It is known to all women and children. Huang Tingjian, although he was a big official, with many domestic servants, but he "Do cleaning and washing every day and never miss his job." Other things also must be his personal care. There are greatly filial sons in history books in every dynasty of Huang family. Huang Shu in the Jin dynasty, showed his filial obedience when his parents were alive. After his parents died, they guarded the tombs and were honored by the government. Later generations established a temple for him as a shrine. After more than a thousand years, the great scholar Tang Xianzu also wrote "The temple for the dutiful son Huangjin in Dongguan County in Jin dynasty." In addition, there are Huang bian in Tang dynasty, Huang Zhou, Huang Heng, Huang Jiayou, Huang Rui in Tang dynasty .Huang Deyu and Huang Guanxiang in the Song dynasty, Huang Liang in Ming dynasty and so on. Chinese Celebrity Dictionary contains hundreds of Huang character's life story, almost $1 / 10$ in which can be said to be filial piety model. So Gu Qing in Ming dynasty praised it: "The Huang family is pure filial piety, along the whole time of life, therefore, the root is from the heart and to the matter, inherent to oneself."

\section{THE PIONEERING SPIRIT FOR ENTREPRENEURSHIP IN ALL OVER THE WORD}

From first to last, Huang family is also permeated with a kind of pioneering spirit faces along with the continuous migration process in the process of the formation, development, and expansion. Of course, the reasons for migration are complex, which sometimes is conscious and active and sometimes forced and helpless. A lot of Huang family tree can see that, in many cases, there are voluntary ingredients, some parents' command, and some work needs. We think, anyway, as long as we dare to walk out of the house, there is a pioneering spirit of ambition.

Historians and anthropologists confirmed that the birthplace of Huang family should be one of the sources of Inner Mongolia on the East Liaohe River water called "Huangshui" (later renamed the "lake water area"). And then constantly migrated, they first got into Shandong peninsula and survived in the harsh conditions of the ancient living environment and the brutal competition of the tribes. In the end, they were always strong and settled in central plains, formed a Huang clan worshipped yellow. They established country Huang in the Xia Dynasty, through the Xia, Shang, Zhou three generations more than two thousand years. The pioneering spirit of Huang ancestors make people awestruck.

In the late spring and Autumn Period, after the death of the Huang kingdom, someone stayed in the hometown and stuck to their homeland, someone drifted in the four corners of the earth and built their homes from scratch. In the warring states period, the Huang family, represented by Chunshenjun Huang Xie, finally thrived and a large number of Huang tribe habitation with the word "Huang" was remained just like Huang Pi, Huang Gang, Huang Mei, Huang An, Huang Dun and Huangpu River (also called Chunshenjiang) etc.

Huang family realized that they need to expand in the nonlocal and this was recorded genealogical. But the most typical should be the feat of Huang Xiaoshan in Fujian province. When he was in his $80 \mathrm{~s}$, he asked 3 eldest sons of 21 sons of his fathers to serve in the hometown, and the other 18 were to go everywhere to find a way out and create a foundation. Huang Xiaoshan solemnly warned: a good man should not stay in love with his native land; he should look around the world and aim for the whole world. He encouraged his sons by poem: "it is determined by the day that if a man will become strong and seven feet man should be independent". The faces of the pioneering spirit and the broad mind around the world inspired his descendants to learn to adapt to new circumstances and create new achievements. The pioneering spirit that inspired the descendants of Huang family was summed up as: Magnify the eye and be in danger; to be in the square, not to miss the hometown; Adapt to the environment and be strong and confident. 


\section{The Unique Tradition of Reciting the PoEm to RECOGNIZE THE CLAN}

Among the domestic and overseas Huang clan, there is a traditional way, which is: recite the poem to recognize the clan. Chinese, especially Han Chinese, tended to have a popular habit of asking "what's your last name?" when meeting and talking. Once you know that you are of the same family name, you often ask the Diwang (namely "junwang") to recognize the clan. Some people surnamed Huang is also like this. But Huang family has a unique way to recognize the family, which is recited "ancestral poems" even "Mother poetry". In his book the book of Chinese Surnames, Mr. Liu Youping said: This is "a special set of cultural codes." Whether at home or abroad, and whether in the mainland or in Hong Kong, as long as one can recite the "password" of this group of people, he can be accepted by the family and be warmly treated. The "identify ancestors poem" of Huang family is from the famous man Huang Xiaoshan. The poem includes 8 sentences. He wrote the poem to encourage his sons to leave their hometowns for business and recite it to his sons personally. It is called "The extra eight sentences". Legend has it that his wife's eight sentences are called "ancestral mother poems" or "The in eight sentences". These two poems are often recorded in many Huang clans. But what needs to be said is that maybe it's because of the ages, maybe it's because of the transfer, there's a lot of difference between the two poems in the genealogy. Therefore, in order to avoid misunderstanding, in Qianlong 46 years (AD 1781) in Qing dynasty, the representatives of Chaozhou, Meizhou and Huizhou were jointly deliberated for a unified revision when Huang family shrine was built in Chaozhou City. The post is now recorded for research and reading.

"The extra eight sentences" is also called "Launching poems" and the whole poem is "To ride a horse to make a different frontier, to appoint from everywhere. Year after year, the country is home. Don't forget the words from family, pray for the ancestors in the morning and evening. I hope that the sky will be blessed and the men will remain best forever."

"The in eight sentences" is also called "Dismounted poems". It is generally believed that a poem for children written by two wives of Huang Xiaoshan Shangguan and $\mathrm{Wu}$ when they sent off their sons and everyone wrote 4 sentences. There are some other people think that the poem was written by 3 wives of Huang Xiaoshan and his eldest son. Everyone wrote 2 sentences. The content is "He was a very old man with three wives and 7 sons, the wives surnamed Shangguan, Zheng and $\mathrm{Wu}$. Starting a business from the homeland, and returned to the family to requite favors. I think it will be difficult for me to meet you. No matter you are rich and poor, you must be in the same family."

\section{CONCLUSION}

The Chinese Huang family people have a distinct personality. This character is gradually formed in the long river of its historical development, which is formed by the interaction with other family members. The Huang family has been adhering to the fine tradition of the Chinese nation culture, the Huang family's culture has enriched the cultural treasure of the Chinese nation, the Huang family's personality traits revealed the spiritual wealth of the Chinese nation.

\section{REFERENCES}

[1] Chen Jiankui, Huang Ming, a Brief History of Huang, [M] Jiangxi people's publishing house, 2014

[2] Huang Zeling, The Great Migration of Immigrants [M] Contemporary China press, 2001

[3] He Bingwu, Yellow Emperor and Chinese culture [M], Shaanxi tourism publishing house, 1999

[4] Wu Shenghui, Chinese Surnames. [M] Hebei people's publishing house, 2006

[5] Chen Jiankui, Chinese Surname Culture [M] Zhongyuan peasant press 2008

[6] Liu Youping, Chinese last name, Huang. [M] Hainan publishing house, 1993

[7] Dong Suyun, The Construction of National Welfare and National Identity [J] Guangxi national university, 2010 